\section{El futuro de los jóvenes como objeto de reflexión sociológica: una práctica de extensión de educación experiencial en escuelas secundarias de la ciudad de Santa Fe}

\author{
Luciana Serovich \\ luserovich@hotmail.com.ar \\ (iD) orcid.org/0000-0001-8670-0195

\section{Josela Garcilazo} \\ garcilazo.josela@gmail.com \\ (iD) orcid.org/0000-0003-0008-6951 \\ Virginia Trevignani \\ trevignani@yahoo.com \\ (iD) orcid.org/0000-0003-3880-8040
}

RECEPCIÓN: 25/04/20

ACEPTACIÓN FINAL: 11/06/20

\section{Resumen}

Ante la integración creciente de la extensión y la educación experiencial en el currículo de la Universidad Nacional del Litoral, este artículo presenta una serie de encuentros y dispositivos didácticos que desarrollamos desde la cátedra de Introducción a la Sociología en una Práctica de Extensión de Educación Experiencial. A partir de las herramientas que brinda la sociología, esta práctica tuvo por objeto reflexionar con los estudiantes de la cátedra y de las diferentes escuelas con las que articulamos a lo largo del proyecto sobre la incertidumbre que atraviesan los jóvenes al finalizar la etapa de educación obligatoria. Aquí presentamos los principales lineamientos teóricos que delinearon la práctica, la centralidad de la actitud de "desnaturalización" en los dispositivos pedagógicos propuestos y los hallazgos y aprendizajes obtenidos a partir de la experiencia.

Palabras clave: extensión universitaria; sociología; jóvenes; transición; educación

\author{
Melania Stehli \\ melaniastehli@gmail.com \\ (iD) orcid.org/0000-0001-9027-7131 \\ Universidad Nacional del Litoral, \\ Argentina.
}

Sujetos y relaciones en extensión universitaria / Intervenciones

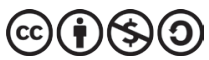

O futuro dos jovens como objeto de reflexão sociológica: uma prática de extensão da educação experiencial em escolas secundárias de Santa Fe

\section{Resumo}

Dada a crescente articulação entre extensão e educação experimental no currículo da Universidade Nacional del Litoral, este artigo apresenta uma série de reuniões e dispositivos didáticos que foram desenvolvidos pela disciplina Introdução à Sociologia em uma Prática de Extensão de Educação Experimental. Essa experiência teve como objetivo refletir, a partir das ferramentas da sociologia, com os alunos da cadeira e com as diferentes escolas com as quais articula ao longo do projeto, sobre a incerteza sobre o futuro que atravessa a juventude no contexto específico da conclusão da etapa obrigatória da educação. Apresentamos aqui as principais diretrizes teóricas que descrevem uma prática, a importância da atitude de "desnaturação" nos dispositivos pedagógicos propostos e os resultados e aprendizagens obtidos a partir da experiência.

Palavras-chave: extensão; sociologia; juventude; transição; educação

Para citación de este artículo: Serovich, L.; Garcilazo, J.; Trevignani, V.; Stehli, M. (2020). El futuro de los jóvenes como objeto de reflexión sociológica: una práctica de extensión de educación experiencial en escuelas secundarias de la ciudad de Santa Fe. +E: Revista de Extensión Universitaria, 10 (12. Ene-Jun), 1-15. doi: 10.14409/extension.2020.12.Ene-Jun.9084. 


\section{Introducción}

La extensión constituye una de las funciones sustantivas de la universidad a través de la cual esta institución canaliza distintas instancias de compromiso social a partir de la implementación de acciones concretas, junto a otros actores sociales, a los fines de transformar situaciones que visibilizan como problemáticas (Beltramino y Theiler, 2017). A su vez, dentro de la amplia gama de acciones enmarcadas en dicha función sustantiva, la Universidad Nacional del Litoral (UNL) viene demostrando hace ya más de diez años un marcado interés por integrar la extensión con la docencia, promoviendo el desarrollo de enfoques conceptuales que permitan concebirla multidimensionalmente, contemplando aspectos institucionales, comunicacionales, sociales, políticos y pedagógicos (Menéndez y Tarabella, 2016, p. 97).

En este marco, surgen las Prácticas de Extensión de Educación Experiencial (PEEE), concebidas como actividades curriculares con diversos niveles de interacción e intervención en el medio social, cultural y productivo local. La educación experiencial se cimienta en una estrategia de enseñanza y construcción de conocimiento con enfoque holístico y relaciona el aprendizaje académico con la vida social, es decir, media la adquisición de conocimientos con la práctica experiencial. Para lograr este objetivo, toda PEEE se despliega en un espacio curricular específico desde el cual se proponen prácticas pedagógicas que promueven instancias de formación que trasciendan las lógicas tradicionales y que, además, aporten a la resolución de problemas sociales.

En este artículo damos cuenta de una experiencia particular e innovadora de articulación entre la sociología, la extensión y la docencia implementadas por la cátedra Introducción a la Sociología (ISO) de la carrera Licenciatura en Sociología de la Facultad de Humanidades y Ciencias (FHUC) de la UNL, que fue denominada "Desnaturalizando la condición juvenil a partir de las prácticas educativas de jóvenes de la ciudad de Santa Fe". ${ }^{1}$

Con relación a los ejes que se proponen en la revista, este artículo busca recuperar nuestra experiencia de extensión al destacar principalmente algunas de las cualidades de los sujetos con los cuales interactuamos, por qué los elegimos y de qué manera buscamos establecer relaciones horizontales con ellos, haciéndolos participes como protagonistas de los aprendizajes y poniendo en el centro de la práctica sus conocimientos y preocupaciones.

De esta manera, esta práctica extensionista se convirtió en un escenario institucional propicio para canalizar algunas de nuestras inquietudes y compromisos ${ }^{2}$ (Elias, 1990) en torno a la inclusión educativa a través de la potencialidad de la mirada sociológica e integrando la docencia, la investigación y la extensión a las clases de esta materia del primer año de la carrera.

La sociología estuvo atravesada desde sus orígenes por una vocación de transformación del mundo social sobre el cual buscaba reflexionar y aspiraba a entender. Los llamados "clásicos" de la sociología construyeron los cimientos de esta ciencia y motorizaron diversos

1) Además de las autoras de esta publicación, el equipo de la PEEE durante el año 2019 estuvo constituido por la titular y la Jefa de Trabajos Prácticos de la cátedra, Virginia Trevignani y Tamara Beltramino, respectivamente. Asimismo, participaron: tres adscriptos en extensión, Josela Garcilazo, Felipe Ojalvo y Luciana Serovich; el ayudante-alumno Carlos Iruretagoyena; y las tutoras de la carrera Yamila Manzur y Antonella Chiconi. Sus aportes no solo fueron sustanciales para el desarrollo de las acciones sino también para la reflexión sobre el proceso que motivó la escritura de este artículo.

2) A propósito de la relación entre las preocupaciones sociales del sociólogo, Elias sostiene que "también los científicos (...) permiten que sus deseos e inclinaciones personales desempeñen algún papel en su trabajo; con bastante frecuencia se ven influidos por determinados intereses de grupos a los que pertenecen" (1990, p. 14). 
cuestionamientos al orden social. En sus producciones sociológicas, los padres fundadores de nuestra disciplina desnaturalizaron las lógicas de funcionamiento del mundo social y evidenciaron, especialmente, cómo se reproducen las desigualdades sociales.

Este espíritu de la sociología, que instaba a colocar los conocimientos al servicio de mejorar la sociedad, se puso en juego en la implementación de esta práctica de extensión. La misma tuvo por objeto la doble tarea de aportar a la comprensión y aprendizaje de los estudiantes secundarios e ingresantes de la carrera de los conocimientos y herramientas que proporciona la sociología, invitándolos a cuestionar prenociones sobre el mundo y su funcionamiento. Para ello, nos propusimos visibilizar de qué modo el sentido común construye explicaciones sobre diversas problemáticas, poniendo el foco en los posibles cursos de vida futuros que los jóvenes imaginan al finalizar la etapa de educación obligatoria.

El presente escrito se estructura en cuatro apartados. En el primero, se establecen los lineamientos generales de la PEEE, los antecedentes de la misma y los objetivos perseguidos. En el segundo apartado se presenta el marco teórico y conceptual respecto de las acciones desarrolladas a lo largo del proyecto. Por último, se describen algunos de los dispositivos pedagógicos que se pusieron en juego en los encuentros con las instituciones educativas y se destacan las cualidades de la dinámica grupal durante su implementación. En tercer lugar, se comentan los desafíos que emergieron en el transcurso de los encuentros y se señalan algunas de las reflexiones con relación a los sujetos sociales con los cuales interactuamos. Por último, se describen aquellos desafíos pedagógicos, extensionistas, investigativos y sociales que supuso esta PEEE, así como las posibles líneas de trabajo a futuro.

\section{La extensión y el aprendizaje experiencial}

Al identificar instituciones educativas de enseñanza secundaria que compartían nuestro mismo interés por reflexionar sobre los proyectos educativos y laborales de sus jóvenes, consolidamos el vínculo extensionista en un trabajo articulado. En efecto, este proyecto nació en el año 2017 a partir de intercambios con docentes de la Escuela secundaria № 481 Esteban Echeverría, que fue la primera institución contraparte de esta propuesta.

A través de investigaciones realizadas de forma previa y de los encuentros realizados con las escuelas observamos que, tras finalizar la etapa de escolaridad obligatoria, los jóvenes desplegaban recorridos e itinerarios variables en la transición hacia la vida adulta (Pacífico, Mantaras, Trevignani, Beltramino y Sejas, 2019). Estos cursos de acción se percibían como elecciones y deseos atravesados por escenarios de incertidumbre, materializados en decisiones ligadas al futuro laboral, asociadas a la independencia personal, a la conformación de una familia propia, o a la posibilidad o no de continuar estudiando. Dado que estos procesos suelen ser experimentados e interpretados como decisiones individuales y no como el producto de condicionantes sociales, la sociología como disciplina ofrece herramientas que habilitan una aproximación distinta. Desde entonces, el problema que se procuró atender desde esta PEEE fueron las incertidumbres sobre el futuro de algunos jóvenes de nuestra ciudad que finalizan la etapa de educación obligatoria atendiendo a sus prácticas y experiencias.

Luego de una primera etapa de trabajo contactamos con otras escuelas, con las que se trabajó articuladamente a lo largo de 2019, sumando un total de cinco instituciones de educación secundaria de la ciudad de Santa Fe: Escuela Secundaria de la UNL, Escuela Echeverría, Colegios San José de Guadalupe, San Eugenio de Mazenod y Sara Faisal. Con algunas de 
ellas ya existía un vínculo previo - como en el caso de la Escuela de la UNL y la Escuela Echeverría-, con otras el diálogo se inauguró durante ese ciclo lectivo. Las instituciones educativas fueron diversas en ubicación geográfica y en tipos de gestiones — públicas y privadas-, lo que nos permitió observar cómo los estudiantes se enfrentaban con diferentes problemáticas sociales, culturales y educativas al momento de terminar su educación secundaria.

Como equipo de PEEE visitamos cada una de estas escuelas y desplegamos distintas propuestas junto a los docentes y equipos de trabajo de los establecimientos educativos. Allí invitamos a los jóvenes a problematizar las experiencias y significados asociados a los procesos de transición a la vida adulta, su percepción sobre el futuro y sus elecciones laborales y profesionales en una etapa -la finalización de la educación obligatoria- de transición institucional, en la que son instados a tomar múltiples decisiones.

Asimismo, como se trata de un proyecto de extensión de educación experiencial, lo anterior se desarrolló en el marco de prácticas docentes centradas en la experimentación de dispositivos que problematizaran las prácticas pedagógicas tradicionales. Para eso, repensamos y resignificamos los modos de enseñar y aprender sociología e ideamos estrategias didácticas novedosas que permitieran la apropiación de herramientas disciplinarias, tanto de los estudiantes de primer año de la carrera de Sociología como de los estudiantes de las escuelas secundarias. Construimos escenarios de aprendizaje para un acercamiento a la disciplina que los "ayudara" a visibilizar diversos aspectos de sus biografías individuales en el contexto social e histórico en el que se desarrollaban, invitándolos a poner en práctica el oficio del sociólogo de forma experiencial y desde los primeros pasos en la carrera, aproximándolos a la disciplina como un saber-hacer y no como un saber meramente teórico.

El supuesto que nos guió fue es que los estudiantes construyeran conocimientos en relación con situaciones, casos, problemas o proyectos cercanos a sus propias experiencias, en tanto estos proyectos contemplaban la idea de que los conocimientos se crean a partir de la transformación de la propia experiencia, y eso obliga a repensar las prácticas de extensión integrándolas al currículo, "promoviendo que los estudiantes se involucren en la resolución de problemas reales en escenarios complejos" (Menéndez y Tarabella, 2016, p.102).

Para llevar a cabo esta PEEE elaboramos e implementamos diferentes dispositivos pedagógicos, diseñados sobre la base de los contenidos y de la experiencia acumulada en la cátedra Introducción a la Sociología. Así, buscamos que la forma de enseñar y aprender de cada dispositivo se encontrara en sintonía con los saberes aprendidos en este espacio curricular, concibiéndolo como un proyecto pedagógico asentado sobre el principio de unidad y como reservorio de saberes generales y profesionales, actitudes y atributos personales considerados indispensables y convenientes en los términos de una definición de formación académica y profesional (Camilloni, 2013, p.12).

Cada uno de los dispositivos pedagógicos fue ideado con el fin de promover un aprendizaje "holístico" basado en estrategias de enseñanza "destinadas a relacionar el aprendizaje académico con la vida real" (Camilloni, p. 15). Esta autora señala la importancia que tiene en la extensión proponer actividades que permitan pensar la conexión entre lo que se aprende en el aula y la propia práctica. Tal vez por esto, todo proyecto de extensión supone plantear un vínculo particular entre los distintos actores sociales, sustentado en la acción intersubjetiva -y no mediante relaciones asimétricas- para la problematización, concientización, reflexión y el cambio (Rafaghelli 2013, p. 23). 
Muy a menudo se percibe en las aulas que se transmite la ciencia como un "valor en sí mismo", no se toma como materia prima a la experiencia humana, y es a partir de esa práctica que surge la pregunta del "para qué se enseña lo que se enseña". No por nada los alumnos expresan su disconformidad con respecto al hecho de que "en las clases no se habla de los temas que les interesan o preocupan". Según Máximo Chaparro, "el debate sobre el valor del conocimiento cotidiano y sus relaciones con el conocimiento escolar y el científico adquiere hondura ante la crisis de los sistemas educativos pensados para un tiempo que ya no es" (2006, p. 423).

Por lo tanto, afirma el autor, enseñar a preguntar es el más perfecto desempeño educativo, puesto que hace que una mayor presencia de "saber cotidiano" en el "saber enseñado" sea la clave para crear educadores y educandos que practiquen un "conocimiento inteligente" en el mundo social contemporáneo. Generar un puente entre "realidad" y "ciencias" resulta fundamental para poder suscitar procesos de "admiración", "asombro", o "preguntas" sobre el mundo social en el que se vive, y más si el objeto específico que se analiza de ese mundo social son las percepciones del propio grupo de estudiantes.

Así, nos interesaba repensar una propuesta de extensión de educación experiencial en la que los saberes surgieran de la construcción conjunta y de la interrelación con la vida real, es decir, "romper" el tipo ideal de aprendizaje académico tradicional basado en la transmisión de conocimiento.

\section{La operación de desnaturalización viabilizada por dispositivos pedagógicos}

En este segundo apartado describimos el marco teórico y conceptual que acompañó la toma de decisiones y los encuentros desarrollados a lo largo del proyecto. Los aportes de autores clásicos como Émile Durkheim, y autores modernos como Pierre Bourdieu, fueron centrales para construir la propuesta inicial, para reflexionar sociológicamente junto a los alumnos en los encuentros y para poder revisar las acciones llevadas a cabo durante toda la práctica. Asimismo, se describen aquí algunos de los dispositivos pedagógicos que se pusieron en juego con las instituciones educativas y se destacan las características particulares de las dinámicas grupales durante la implementación.

\section{La reflexión desnaturalizada como herramienta de intervención social}

En sintonía con conceptos claves de la materia Introducción a la Sociología, una de las tareas principales fue poner en evidencia - como establece E. Durkheim- determinados hechos sociales, entendidos como formas de hacer, pensar o sentir "susceptibles de ejercer sobre el individuo una coacción exterior (...), independiente de sus manifestaciones individuales" (2000, p. 6).

Es este sentido, construir una mirada sociológica sobre los condicionamientos sociales del sufrimiento individual resulta no solo una acción liberadora, sino un mecanismo habilitante de decisiones impensadas en circunstancias no elegidas, al mostrar el carácter no natural de los "destinos". De ahí que trabajar con jóvenes en etapa de escolarización secundaria y reflexionar junto a ellos en torno a sus propias trayectorias vitales, escolares, laborales y profesionales, pueda ser útil para desnaturalizar las elecciones y reinterpretarlas en el marco de las tramas sociales que las condicionan y producen, haciendo de la desnaturalización una 
herramienta reflexiva para comprender los modos de experimentar subjetivamente destinos "probables" como los "únicos" destinos.

El desconocimiento de los condicionamientos sociales engendra diversos mecanismos de responsabilización individual, estigmatización, y conlleva la reproducción de las desigualdades sociales (Bourdieu y Passeron, 1973), generando percepciones de incapacidad, sinsentido y malestar individual. $Y$ aunque "hacer conscientes ciertos mecanismos que hacen dolorosa e incluso intolerable la vida no significa neutralizarlos, sacar a la luz las contradicciones no significa resolverlas" (Bourdieu, 1993, p. 559), con estas herramientas los estudiantes reconocen el origen social de aquellos sentimientos y reconstruyen la trama de instituciones que intervienen en la producción de estos destinos.

El desafío fue grande, pues se trataba de generar los medios pedagógicos para que la interpretación no recayera en sujetos, personas, aspectos sustantivos, o teorías conspirativas, y de que se evitara mistificar o buscar "chivos expiatorios", muy usuales dentro del sentido común.

Por eso, las operaciones cognitivas de cuestionamiento, andamiadas de forma pedagógica y didáctica que nos ofrece la desnaturalización, resultaron efectivas y produjeron —desde nuestra perspectiva - movimientos capaces de desmontar sentidos aprehendidos, volviéndose un recurso subjetivo y colectivo de transformación de los cursos de acción.

\section{Construir escenarios para el aprendizaje de una mirada: la actitud científica como medio}

Desde el comienzo tuvimos claro que los jóvenes eran quienes debían llevar a cabo las acciones de interpretación y reflexión. No se trataba de realizar transferencias o de impartir conocimientos. La gran pregunta que se abrió para nosotros fue: ¿cómo hacer para enseñar la mirada sociológica sin tener que hablar sobre Durkheim, Weber o cualquier autor contemporáneo? ¿Cómo enseñar y aprender sociología en un proceso colectivo de intercambio, en donde las historias de los actores sean el eje de la reflexión y, al mismo tiempo, no se convierta en un "grupo de autoayuda"?

La solución fue construir escenarios didácticos que otorgaran centralidad a lo que llamamos "actitud científica". Es decir, estrategias didácticas cuyas dinámicas permitieran promover el aprendizaje de esa actitud científica frente al mundo social naturalizado. Estimular la adopción de "esa mirada" por parte de los jóvenes implicaba construir primero escenarios de distanciamiento y luego de revinculación con sus creencias en torno al futuro mediante una renovada capacidad de sorpresa, asombro y extrañamiento.

Debíamos proponer consignas que posibilitaran plasmar de forma ordenada y sistematizada los relatos emergentes del intercambio, de modo tal que pudieran ser resignificados desde una nueva perspectiva, distanciada, capaz de objetivarlos y "despersonificarlos".

Esta búsqueda por explicitar el carácter social de las decisiones aparentemente más individuales o "íntimas" no podía producirse violentando simbólicamente la interacción, especialmente en el contexto áulico, donde las desigualdades operan desde la propia disposición de los cuerpos y atraviesan la configuración institucional de los espacios (cómo nos sentamos, hablamos, nos dirigimos a los docentes, etc.). En este sentido, fue preciso garantizar los recaudos en la recopilación de sus relatos y la puesta en común de las percepciones para evitar cualquier tipo de situación incómoda. Por eso algunos dispositivos funcionaron a par- 
tir de relatos anónimos mientras que, en otros casos, se utilizaron elementos disparadores "neutrales" para salirse de lo "personal".

A continuación, daremos cuenta de cuatro de los dispositivos pedagógicos. Estos se caracterizan por su diseño flexible, lo que nos permitió adecuarlos a las circunstancias institucionales específicas, con sus problemáticas juveniles, sus tiempos, sus materiales y espacios disponibles, y nos propuso, al mismo tiempo, el desafío de reformular sobre la marcha la mejor forma de implementarlos.

\section{a) La canasta de los futuros posibles}

Mediante este dispositivo se tomaron como eje estructurador de la reflexión los proyectos a futuro de estos jóvenes - a largo y corto plazo- durante su proceso de transición a la vida adulta. Los interrogantes generales que movilizó el dispositivo fueron: ¿cómo construyen estos jóvenes las expectativas sobre el futuro? ¿Qué factores sociales y tramas institucionales inciden en la construcción de creencias y expectativas profesionales o laborales?

La actividad pretendía construir un escenario en función de que los jóvenes respondieran de forma anónima una serie de preguntas que apuntaban a reponer qué les gustaría hacer al terminar la escuela, si tenían aspiraciones laborales y de qué tipo, para que, en un segundo momento, sus respuestas fueran ordenadas y convertidas en datos a interpretar. Estos, proyectados a través de diversos soportes tecnológicos, hacían posible observar regularidades y diferencias emergentes y abrían así la discusión sociológica colectiva sobre los deseos y las decisiones "personales": ¿qué datos llaman más su atención? ¿Cuáles son las elecciones más frecuentes? ¿Cuáles son las menos frecuentes? ¿Por qué será esto? ¿Qué nos dicen estas aspiraciones de nosotros como jóvenes? ¿Cómo podríamos relacionar las elecciones según el género y/o la edad? ¿Cómo podemos relacionar estas decisiones "personales" sobre lo que nos gustaría ser y hacer en el futuro con los grupos a los que pertenecemos?

\section{b) El juego de las estaciones}

En esta actividad, se presentaban a los estudiantes tres "estaciones" (simuladas con afiches), cada una de ellas bajo el nombre de: a) La estación de lo "inmutable", b) La estación de lo "imposible", y c) La estación de lo "inevitable". En la primera estación, cada joven debía identificar esas cosas o actividades que, desde su percepción actual, creía que nunca dejarían de gustarle a lo largo de su vida. En la estación de "lo imposible" se los invitaba a identificar aquello que les parecía que estaba fuera de sus posibilidades reales, es decir, los sueños que desde su percepción resultaban imposibles de alcanzar. En la estación de "lo inevitable" se los invitaba a enunciar aquello que creían que finalmente iban a terminar haciendo al finalizar los estudios secundarios, es decir, lo más "probable".

Luego de que cada estudiante anotara de manera anónima e individual sus respuestas en papeles, el equipo de trabajo se encargaba de sistematizarlas en cada una de las "estaciones", respectivamente, para que luego, frente a esta información organizada bajo distintos criterios, pudiéramos encontrar patrones comunes y diferencias hacia el interior y entre cada estación, y problematizar las regularidades.

Atendiendo a la flexibilidad anteriormente mencionada, esta última actividad fue implementada en distintas instituciones aplicando algunas variaciones. Por ejemplo, hubo un caso en donde se incorporó una nueva estación sobre los "miedos", en donde a la reflexión ante- 
rior se sumaba la percepción subjetiva de los temores con relación al futuro, lo cual permitió interpretarlos como producto de condiciones sociales más amplias marcadas por contextos de incertidumbre estructurales.

\section{c) Desnaturalización sociológica de objetos}

Aunque la mayoría de las veces "esencializamos" las cosas por el grado de familiaridad que sentimos con ellas, la existencia de todo objeto o tecnología se vincula con formas de relaciones humanas más amplias que le dan su sentido social y, por ello, todo objeto es susceptible de convertirse en un medio de indagación sociológica.

En este dispositivo pedagógico el debate colectivo se estructuró en torno a la existencia y modos de usos de una serie de objetos, antiguos y contemporáneos, ligados de alguna manera al mundo del trabajo. ${ }^{4}$ El propósito fue buscar conexiones entre dichos objetos y el tipo de organización actual de los mundos del trabajo, las relaciones sociales que estructuran los mercados laborales, sus vínculos con actividades cotidianas, o con prácticas más bien ligadas a las mujeres o a los varones, etc. De este modo, se visibilizaron diferencias de género, de posición social e incluso de trayectorias formativas y su incidencia en la definición de los futuros posibles de los jóvenes.

Para guiar el debate, se planteó oralmente una serie de preguntas que funcionaron a modo de disparador: ¿para qué sirve o fue inventado este objeto o tecnología? ¿En qué tipo de trabajos se utiliza normalmente? ¿Tiene un único uso social posible? ¿Qué tipo de organización social del trabajo supone la existencia de ese objeto? ¿En qué época apareció? ¿Qué tipo de trabajador supone la existencia de esa tecnología? ¿Qué creencias o supuestos aparecen naturalizados en él? ¿Con qué otras características de las sociedades se vincula la existencia de ese objeto?

\section{d) Aprendices de investigación}

Este es un dispositivo ${ }^{5}$ que, a partir del protagonismo de los participantes en el relevamiento de datos y el trabajo reflexivo sobre la propia investigación, puede ser utilizado con fines diversos. En esta oportunidad, dados los objetivos del espacio, lo usamos para mostrar cómo la indagación y la lectura de los datos en clave sociológica habilitan a repensar las diferentes maneras en que se construyen las representaciones sobre la educación superior, al mismo tiempo que nos permitió poner en práctica el oficio del sociólogo.

Los participantes -estudiantes universitarios y de escuelas secundarias de la ciudadrealizaron encuestas a estudiantes universitarios y registraron con sus celulares en un formulario online las respuestas a tres preguntas: 1) ¿Para qué sirve la educación universitaria?; 2)

3) Esencializar algo significa otorgarle el carácter de una "cosa", volverlo algo "natural", inmutable, inerte, algo con existencia propia. Es entenderlo como una esencia, en vez del producto de relaciones sociales históricas y variables. Para comprender eso, el ejercicio de transformar los sustantivos en verbos convierte las cosas inmutables en procesos siempre cambiantes.

4) En las escuelas en las que utilizamos este dispositivo, los objetos presentados mediante imágenes impresas, en algunos casos, como los objetos físicos reales, en otros, fueron los siguientes: una pinza, una mochila de "Pedidos ya", un apartado para sacar leche, un güiro, entre algunos otros.

5) Desde la cátedra de Introducción a la Sociología gestamos esta idea a través de diferentes ejercicios que se consumaron luego en el dispositivo Aprendices de Investigación, que no solo fue utilizado en el marco de esta práctica de extensión sino también en las pruebas piloto del nuevo ingreso a la UNL en las instancias 2019 y 2020. 
¿Por qué estudiás? y 3) ¿Cuáles son tus sueños a futuro? En simultáneo, otros integrantes del equipo hicieron el procesamiento armando "nubes de palabras" que se presentaron a los jóvenes, quienes debatieron colectivamente los resultados obtenidos.

Este dispositivo posibilitó trabajar con los participantes de manera "distanciada" los datos recolectados, de manera de objetivar dicha información, haciéndole preguntas, cuestionándola, y reflexionando con respecto a ella. En fin, la puesta en funcionamiento del dispositivo es una vía más para lograr la desnaturalización, ubicando al estudiante como protagonista del proceso investigativo.

Cabe aclarar que la implementación de este dispositivo tuvo la particularidad de desarrollarse en el campus universitario y no en las escuelas. Esta vez, los estudiantes fueron invitados a acercarse a la universidad y durante esa jornada trabajaron juntos casi setenta estudiantes de distintos espacios educativos: alumnos de primer año de la cátedra de Introducción a la Sociología, alumnos de 5to. año de la Escuela Secundaria de UNL, y alumnos de 5to. año de la Escuela Secundaria Esteban Echeverría.

La sorpresa que suscitó la proyección de los resultados de las encuestas sirvió como un gran disparador para habilitar un diálogo conjunto en torno a las representaciones, creencias y percepciones que estos jóvenes tenían sobre el futuro, el trabajo y la universidad como destino posible, según su origen social. Mientras que algunos manifestaron su deseo de recibirse en una carrera universitaria, otros explicaron que no se imaginaban trabajando "encerrados en una oficina" sino más bien "haciendo algo con su cuerpo", por ejemplo, un oficio.

El contraste entre las diversas percepciones puso en evidencia las diferencias que habitaban el espacio, lo que redundó en un ejercicio de aprendizaje y desnaturalización al mismo tiempo que permitió el encuentro entre jóvenes de diversos universos sociales a través del ejercicio de puesta en práctica de las herramientas sociológicas.

\section{Algunas observaciones generales sobre la implementación de los dispositivos en las escuelas}

Las actividades ideadas nunca constituyeron un fin en sí mismo, sino que fueron concebidas como medios para promover y habilitar la palabra de los jóvenes, siempre apuntando a construir un clima distendido y cómodo para un intercambio libre entre estudiantes, graduados y docentes, pues hablar sobre su futuro suponía tratar una temática realmente seria para ellos y por lo tanto requería hacerlo con el compromiso y el cuidado ético apropiados.

Como se pudo observar, cada actividad poseía su propio procedimiento y cualidades específicas. Si "La canasta de los futuros posibles" buscaba colocar el foco en la reflexión de los futuros a corto y largo plazo y su relación con la universidad, el juego de "Las estaciones" ponía el énfasis en los deseos y los miedos de los jóvenes con relación al futuro (laboral y/o educativo), la dinámica de "Desnaturalización de objetos" habilitaba la problematización sociológica en torno a los tipos de trabajos a los que aspiraban los jóvenes, y "Aprendices de investigación", por su parte, permitía objetivar los datos recolectados de manera personal e individual para poder analizarlos en perspectiva y con cierto distanciamiento.

Más allá de sus especificidades, interesa remarcar un rasgo común a todas las dinámicas propuestas: colocar en el centro de la reflexión los relatos y experiencias de los propios jóvenes desde sus expectativas, intereses y temores, de modo de aprender a razonar sociológicamente, favorecer el planteo de preguntas nuevas acerca de asuntos sobre los cuales habían 
reflexionado previamente, en la intimidad del hogar, con afectos e incluso profesionales. La diferencia fundamental fue que se les propuso iluminar otras partes del problema que, por estar muy comprometidos con sus propias elecciones, quizás no habían podido ver previamente.

Así, la PEEE permitió configurar un escenario pedagógico para el ensayo y aprendizaje de una singular actitud frente al mundo que habilite a la sorpresa y la curiosidad acerca de cómo ellos mismos trazan sus trayectorias educativas y laborales. Juntos nos animamos a arriesgar diversas hipótesis en torno a la posible influencia de factores tales como la familia, el género, el barrio o la ciudad que habitamos, la edad, el nivel educativo, la posición económica, etc., en cada uno de los posibles rumbos a tomar.

Al convertirse en protagonistas de las interpretaciones, pudieron descubrir el carácter social de esas decisiones que tanto miedo o angustia les producían y eso los animó a seguir haciendo nuevas preguntas. Las siguientes devoluciones a las actividades realizadas permiten ilustrar su percepción en torno a la experiencia:

"Sentí que todos tenemos gustos parecidos, que la sociedad a pesar de que pensamos que son individuales. Que, a veces, lo que para algunos es posible, para otros es un sueño. Creo que nos puede servir para ver que queremos para nuestro futuro, qué nos gustaría hacer, ver nuestras posibilidades". (Estudiante de 5to. año de Escuela A)

"Al principio me sentí incómoda al tener que hablar de mis miedos, mis gustos, etc. Pero después me sentí re bien y me gustó saber que muchas otras chicas compartían mis miedos objetivos, preocupaciones, etc. Me sirvió mucho para darme cuenta de que, en realidad, los miedos y preocupaciones que yo creía eran solo míos, en realidad los comparto con muchas otras chicas". (Estudiante de 5to. año de Escuela B)

La perspectiva distanciada sobre los mismos, su explicitación y visibilización hicieron factible descubrir que las mismas vivencias estaban presentes en los relatos de sus compañeros. El entusiasmo ante la actividad se evidenció luego de cada encuentro, pues solían quedarse preguntando qué otros temas podrían seguir pensando desde esta mirada problematizadora, mostrando un interés directo en la sociología como disciplina.

Así, como afirma Camilloni (2013, p. 15), la construcción del significado de lo aprendido para el estudiante supone el proceso reflexivo que solo puede ser hecho por el propio sujeto, "un proceso por el cual una vivencia o un conjunto de vivencias se convierte en 'experiencia' y esta en un aprendizaje reconocido como tal" y, por lo tanto, se encuentra en la sociología una utilidad práctica que trasciende al tema específico propuesto por el equipo.

\section{Algunos aprendizajes y desafíos emergentes de los encuentros}

En este apartado se presentan los distintos hallazgos y desafíos que emergieron en el transcurso de los encuentros. Señalamos algunas de las consideraciones que surgieron en cuanto a los sujetos sociales con los cuales interactuábamos, tales como la reflexividad y la revisión constante del proyecto a futuro que deben trazar en esta etapa de la vida. Por otra parte, establecemos en esta instancia el rol central que tuvo durante toda la PEEE la función universitaria de investigación con relación a las otras dos funciones. 


\section{a) Jóvenes hiperreflexivos: la obligación de encontrar un proyecto de vida}

Uno de los hallazgos más importantes durante este proceso fue encontrarnos con jóvenes con una enorme capacidad reflexiva. Esta capacidad no se circunscribe a los jóvenes, así como tampoco es atribuible a cierto tipo de jóvenes. Por el contrario, como argumenta Giddens, la reflexividad es un atributo de la modernidad y se encarna en sus instituciones y en los sujetos. En sus palabras:

"la reflexividad de la modernidad alcanza al corazón del yo. (...) el yo se convierte en un proyecto reflexivo. Las transiciones en las vidas individuales han exigido siempre una reorganización psíquica, algo que en las culturas tradicionales se expresaba en forma de ritos de paso. (...) En cambio, en las circunstancias de la modernidad, el yo alterado deberá ser explorado y construido como parte de un proceso reflexivo para vincular el cambio personal y el social". (1995, p. 49)

Estos jóvenes contemporáneos experimentaban el peso de encontrarse ante la obligación de tener que tomar sus decisiones de un modo cada vez más reflexivo, con la sensación generalizada de que no había rumbos predefinidos ni recetas únicas. La revisión permanente sobre la propia trayectoria ejerce fuerte coerción en la vida individual y convierte las competencias de reflexividad en un registro continuo de toda acción (Giddens, 1993, p. 41). La biografía reflexiva en contextos de individualización es impuesta por la norma del "hágalo usted mismo", con sus consecuentes angustias y sensaciones de incertidumbre.

Sabíamos que para los estudiantes no era algo nuevo el hecho de revisar reflexivamente sus decisiones sino que, por el contrario, con mayor o menor consciencia, era un ejercicio habitual en los más diversos ámbitos de su vida cotidiana. Sin embargo, sí descubrimos con sorpresa su interés por conversar sobre estas preocupaciones con adultos —es decir, con el equipo de la PEEE- ya que ante cada propuesta se veían sumamente interpelados a reflexionar de manera colectiva sobre el momento que estaban experimentando en su trayectoria.

Esta hiperreflexividad de nuestros jóvenes, sumada a su enorme disposición para realizar las actividades propuestas, nos obligó reformular más de una vez, y en la propia experiencia, la dinámica de trabajo. Desde los primeros encuentros quedó en evidencia que el mayor desafío sería el de encontrar la manera que permitiera retomar esta actitud, redireccionarla y reorientarla en función de repensar estas mismas preocupaciones pero desde la perspectiva sociológica, mediante nuevas preguntas que cuestionaran la reflexividad propia del sentido común.

La experiencia en el territorio no tardó en evidenciar lo delicado del asunto ya que, al mismo tiempo que se pretendía ayudarlos a reconocer el carácter socialmente condicionado de su accionar individual, debíamos ser lo suficientemente cuidadosos de no alimentar una visión fatalista que condujera -erróneamente- al pensamiento de que los destinos están estrictamente predeterminados por causas sociales. Reflexionamos acerca de cómo los condicionamientos son coercitivos pero no determinantes, y a pesar de que el accionar individual no sea totalmente libre, posee márgenes de acción posibles. Como ya hemos dicho, creemos que esto constituye un primer paso para revisar las propias elecciones y encontrar alternativas creativas y originales ante las disyuntivas que muchas veces se les plantean para definir el futuro. 


\section{b) Diversas maneras de gestionar futuro(s)}

La recepción y puesta en práctica de los distintos dispositivos no fue igual en todas las escuelas, dado que las instituciones varían según los grupos sociales que las habitan. Así, observamos que mientras para algunos el destino universitario era un horizonte predecible o "normal", para otros la universidad se constituía como un horizonte lejano y debían hacer un "esfuerzo" reflexivo mayor para imaginarla como una posibilidad. En el mismo sentido, descubrimos que muchos estudiantes expresaban con frecuencia su deseo - y la posibilidad de materializarlo- de realizar algún viaje de ocio antes de iniciar sus estudios universitarios, mientras que para jóvenes con menores posibilidades económicas esta opción parecía imposible de ser concebida. Tampoco resultó casual que hubiera jóvenes muy preocupados por encontrar un trabajo que "los haga felices" o cuyos miedos máximos fueran "trabajar de lo que estudió", mientras que para otros el principal temor era el de "encontrar un trabajo seguro".

Asimismo, los jóvenes parecían tener muy definido qué querían para su futuro, pero también estaban aquellos que no lo tenían demasiado claro. Si bien todos estaban inmersos en la incertidumbre (Beck y Beck Gersheim, 1993), las posibilidades de vincularse con esta y gestionar sus miedos y preocupaciones variaban.

En esta misma línea, identificamos distintas maneras de institucionalizar los procesos de elección laboral/profesional de sus estudiantes en cada escuela y variaciones en el impacto de la escuela en la construcción de expectativas a futuro. Las formas en las que esas escuelas secundarias se articulaban, o no, con la educación superior eran diversas: en algunas escuelas esta preocupación estaba incluida como parte de la propia currícula y era usual que entre sus estudiantes emergiera la sensación de hartazgo ante la pregunta acerca de lo que venía luego de la secundaria; en otras escuelas, la gestión de los proyectos a futuro de sus jóvenes parecía quedar más en manos "de los propios individuos". En tales casos, se percibía en ellos una mayor disposición a dialogar sobre estos temas.

Si bien los alcances de este proyecto no permiten sacar conclusiones, nos pareció importante atender al rol de las culturas institucionales en la creación de expectativas de continuar o no estudios superiores. Al respecto, una consecuencia no pensada originalmente que surgió de la intervención fue acercar la universidad a instituciones o grupos sociales para los que este espacio sigue siendo distante e, incluso, desconocido.

\section{c) La investigación como aliada de la extensión y la docencia}

Como mencionamos, esta PEEE se enmarca en dos funciones sustantivas de la universidad, específicamente, las de extensión y docencia. Sin embargo, a medida que implementamos las actividades descubrimos que la otra función —la investigación — no estaba ausente sino que, por el contrario, se articulaba permanentemente con las otras para alcanzar los objetivos.

Las funciones de docencia y extensión estuvieron presentes de forma transversal en todo el proyecto indefectiblemente, pues no debemos olvidar que uno de los principales objetivos de la PEEE es construir, aprender y enseñar saberes de forma experiencial. Como educadores, apuntamos a retomar los saberes del espacio curricular y a seleccionar estrategias pedagógicas innovadoras, dinámicas y lúdicas, que contribuyan a resolver las problemáticas que aquejan a las instituciones educativas.

También debimos ser capaces de implementar cada uno de los dispositivos de modo flexible, adaptándolos a las posibilidades de cada grupo y del territorio, es decir, a las condi- 
ciones materiales disponibles de la contraparte, con sus tiempos institucionales, ejercitando la escucha activa y funcionando como co-constructores del proceso de enseñanza-aprendizaje de las herramientas sociológicas que se buscaba utilizar. La participación activa y responsable de los coordinadores de la experiencia de aprendizaje encargados de "guiar" el intercambio fue central para dar un sentido anclado en la propia experiencia de los estudiantes, salvaguardando su libertad y estimulando al mismo tiempo su creatividad (Camilloni, 2013).

Para nuestra sorpresa, como dijimos, la función de investigación igualmente estuvo presente en diversas instancias de la PEEE. En primer lugar, fue útil para la construcción reflexiva del dispositivo didáctico, ya que nos permitió que el acercamiento previo con cada escuela fuera mediado con entrevistas a referentes institucionales a los fines de conocer y sistematizar las características de los grupos con los que se trabajaría. Se ponían en juego aquí disposiciones tales como la observación, el registro y el análisis. En segundo lugar, la investigación se puso en juego durante el momento áulico, para ayudar construir la "actitud científica del investigador" en cada uno de los dispositivos utilizados, en pos de tomar distancia y suscitar un proceso de abstracción con respecto a las percepciones personales. En tercer lugar, las destrezas investigativas jugaron un rol importante al momento de realizar los registros mediante notas de campo en torno a las particularidades de los procesos de implementación de las actividades en las diferentes escuelas. Este registro nos posibilitó, una vez finalizada la práctica, realizar evaluaciones y reflexiones acerca del cumplimiento de los objetivos planteados, identificar aciertos y dificultades, y proponer ajustes o mejoras para las próximas oportunidades.

Esta interdependencia de las funciones aportó al grupo para no caer en una visión lineal o cerrada de cada función sustantiva y volver sobre la necesidad del diálogo continuo, interdependiente y reflexivo entre ellas, para conseguir la integración real de la universidad con la sociedad de la que es parte. El desafío sigue siendo pensar cuáles son los puentes de articulación no solo entre docencia y extensión sino también con la investigación, de qué forma recrearlos y fortalecerlos. En este sentido, la sociología, con sus particularidades, favorece justamente esta articulación entre la transmisión, la creación de conocimiento y la relación con la sociedad.

\section{Desafíos pendientes}

Esta PEEE puede ser concebida como un ensayo de proyectos pedagógicos innovadores para el cambio social y educativo a través de los trabajos articulados entre la universidad y diversas instituciones escolares. Desde nuestro espacio, y con las limitaciones de los tiempos y los recursos materiales y humanos, intentamos aportar a la construcción de formas pedagógicas dinámicas y experienciales. Por ello, esta práctica constituyó un antecedente de nuevos vínculos entre universidad, escuela y sociología, que consideramos valioso dejar asentado para que otros puedan retomarlo, recrearlo, mejorarlo, o inspirarse en este para desarrollar nuevas prácticas. Creemos en la potencialidad de encuentros de esta naturaleza que apunten a generar instancias de acercamiento entre actores universitarios y de la escuela secundaria.

Si bien, por el momento, no podemos saber el impacto que tendrá nuestro aporte más que a través de algunos indicios sugerentes, sí verificamos gratamente que poner el cuerpo 
en propuestas de construcción colectiva contribuye a la generación de espacios de reflexión en torno a los problemas de un modo creativo y diferente.

Cada encuentro fue un recordatorio de que todavía son muchísimos los jóvenes que tienden a colocar a la universidad en la estación de "lo imposible", aun cuando existe el deseo por acceder a ella, y aparecen asimismo muchos otros que la imaginan como un destino poco probable y tienen demasiados temores en cuanto a poder sostener una trayectoria en los estudios superiores.

Cabe pensar que si una práctica extensionista de este tipo, de conseguir prolongarse en el tiempo, o experiencias educativas similares pudieran ser replicadas, podría tratarse de una ocasión interesante para la observación de las diferentes formas de pensar en la universidad por parte de los jóvenes según los grupos sociales a los que pertenecen y convertirse la propia actividad de intervención en el territorio en una fuente de información valiosa para dar curso a proyectos de investigación. Es decir, estos indicios surgidos en la propia extensión podrían paulatinamente ser incorporados como insumos de reflexión para la elaboración de políticas de inclusión social universitaria por parte de aquellas instituciones educativas preocupadas por recibir a nuevos jóvenes en sus aulas y mejorar sus posibilidades de permanencia.

Queda mucho por aprender y reinventar, pero deseamos ayudar a construir una sociedad capaz de hacer conscientes sus desigualdades con el objeto de poder luchar contra las mismas. La sociología es una voz útil para esto y, por eso, continuaremos suscitando espacios donde poder co-construirla entre todos.

\section{Referencias bibliográficas}

Beck, U. y Beck-Gernsheim, E. (2003). La individualización: el individualismo institucionalizado y sus consecuencias sociales y políticas. Paidós.

Beltramino, T. \& Theiler, J. (2018). Extensión universitaria e innovación social: reflexiones en torno a los vínculos entre la universidad y los actores sociales. +E: Revista de Extensión Universitaria, 7(7), 84-96. https://doi. org/10.14409/extension.v0i7.7053

Bourdieu, P. (2000). Poscriptum. En La miseria del mundo (pp. 557-559). FCE.

Bourdieu, P. y Passeron, J. (2003). Los Herederos. Los estudiantes y la cultura. Siglo XXI Editores.

Camilloni, A. (2013). La inclusión de la educación experiencial en el currículo universitario. En Menéndez, G. y otros. Integración docencia y extensión. Otra forma de aprender y de enseñar (pp 11-21). Ediciones UNL.

Chaparro, M. (2006). Epistemología de la Educación. Perspectiva para una educación del futuro. De los Cuatro Vientos Editorial.

Durkheim, E. (2000). Las reglas del método sociológico. Ediciones Quinto Sol.

Elias, N. (1990). Compromiso y distanciamiento. Ensayos de sociología del conocimiento. Península.

Giddens, A. (1995). Modernidad e identidad del yo. El yo y la sociedad en la época contemporánea. Península. Marqués, V. (1996). No es natural. En Para una sociología de la vida cotidiana. Anagrama.

Menéndez, G. y Tarabella, L. (2017). El aprendizaje experiencial: una práctica de innovación que se afianza en la Universidad Nacional del Litoral. +E: Revista de Extensión Universitaria, 6(6), 96-103. https://doi. org/10.14409/extension.v1i6.6317

Pacífico, A.; Mantaras, B.; Trevignani, V.; Beltramino; T; Sejas, N. (2019). Sujetos, instituciones y trayectorias. Ediciones UNL. 
Rafaghelli, M. (2013). La dimensión pedagógica de la extensión. En Menéndez, G y otros. Integración docencia y extensión. Otra forma de aprender y de enseñar (pp. 22-37). Ediciones UNL.

Sidicaro, R. (2003). La sociología según Pierre Bourdieu. En Bourdieu, P. y Passeron, J.-C. Los Herederos. Los estudiantes y la cultura (pp. IX-XXXII). Siglo XXI Editores. 